\title{
Fast Hemodynamic Responses in the Visual Cortex of the Awake Mouse
}

\author{
M. Andrea Pisauro, Neel T. Dhruv, Matteo Carandini, and Andrea Benucci \\ Institute of Ophthalmology, University College London, London EC1V 9EL, United Kingdom
}

Hemodynamic responses in mice and other species are typically measured under anesthesia. However, anesthesia could influence their relationship to neural activity. To investigate this relationship, we used optical imaging in mouse primary visual cortex (V1). Hemodynamic responses yielded clear maps of retinotopy in both anesthetized and awake mice. However, during wakefulness, responses were four times larger and twice as fast. These differences held whether we induced anesthesia with urethane or isoflurane and whether awake mice were stationary or running on a treadmill. With electrode recordings, we established that the effects of wakefulness reflect changes in neurovascular coupling, not in neural activity. By activating V1 directly via optogenetics, we replicated the effects of wakefulness in terms of timing but not of amplitude. We conclude that neurovascular coupling depends critically on anesthesia and wakefulness: during wakefulness, neural activity is followed by much stronger and quicker hemodynamic responses.

\section{Introduction}

Neural activity is often inferred from measurements of blood responses, typically obtained from blood-oxygen-level-dependent (BOLD) signals acquired in humans with fMRI. To make this inference, we must understand neurovascular coupling: that is, how neural activity relates to blood volume and oxygenation. Neurovascular coupling is thought to involve a cascade of events starting with glutamate release at synapses (Attwell and Iadecola, 2002; Attwell et al., 2010). The resulting hemodynamic response lasts several seconds and reflects the activity of local neurons (Heeger et al., 2000; Logothetis et al., 2001). To a good approximation, hemodynamic signals are simply a filtered version of the neural signals (Boynton et al., 1996; Kahn et al., 2011; Cardoso et al., 2012).

Neurovascular coupling depends on factors influencing physiological state, such as anesthesia and wakefulness. Anesthesia has been shown to decrease the amplitude of hemodynamic responses in humans (Marcar et al., 2006; Qiu et al., 2008), monkeys (Shtoyerman et al., 2000; Chen et al., 2005; Goense and Logothetis, 2008), and rodents (Peeters et al., 2001; Martin et al., 2006; Desai et al., 2011). However, there is disagreement on whether anesthesia also affects the time course of hemodynamic responses. Studies in rats indicate that anesthesia lengthens the

Received May 20, 2013; revised 0ct. 8, 2013; accepted 0ct. 15, 2013.

Author contributions: M.A.P., M.C., and A.B. designed research; M.A.P., N.T.D., and A.B. performed research; N.T.D., M.C., and A.B. contributed unpublished reagents/analytic tools; M.A.P., N.T.D., and A.B. analyzed data; M.A.P., M.C., and A.B. wrote the paper.

This work was supported by the Wellcome Trust and by the European Research Council. M.A.P. was supported by a University College London/Fight for Sight studentship. N.T.D. was supported by a Royal Society Newton International Fellowship and a National Science Foundation International Research Fellowship. M.C. holds the GlaxoSmithKline/Fight for Sight Chair in Visual Neuroscience. We thank Charu Reddy for outstanding technical support and Geraint Rees and David Attwell for comments on this manuscript.

Correspondence should be addressed to Matteo Carandini, Institute of Ophthalmology, University College London, 11-43 Bath Street, London EC1V 9EL, United Kingdom. E-mail: m.carandini@ucl.ac.uk.

DOI:10.1523/JNEUROSCI.2130-13.2013

Copyright $\odot 2013$ the authors $\quad 0270-6474 / 13 / 3318343-09 \$ 15.00 / 0$ latency and time course of the responses (Martin et al., 2006; Masamoto et al., 2009). Conversely, a study in primates reported that anesthesia does not affect time courses (Shtoyerman et al., 2000). This difference in results may be ascribed to differences in species or anesthesia and remains an open question.

Here we investigate these issues with experiments in the primary visual cortex (V1) of the mouse. The mouse is becoming a standard species in systems neuroscience due to the availability of genetic tools for probing and interrogating neural circuits. In particular, it is becoming common to measure hemodynamic responses in anesthetized mice; for example, to measure retinotopy (Schuett et al., 2002; Kalatsky and Stryker, 2003) and its changes after cortical plasticity (Cang et al., 2005; Smith and Trachtenberg, 2007; Kaneko et al., 2008; Sato and Stryker, 2008; Southwell et al., 2010; Merlin et al., 2013) or to assess potential therapies (Pearson et al., 2012). It is therefore important to characterize hemodynamic responses in mice and how they are affected by wakefulness and anesthesia.

We measured hemodynamic responses using optical imaging, both in wakefulness and under anesthesia. We induced anesthesia with two regimes that are common in studies of mouse V1: isoflurane and urethane. To control for the effect of locomotion, we also compared responses when awake mice were stationary versus running on a spherical treadmill. To interpret these results in terms of neurovascular coupling, we recorded neural responses and compared the effects of anesthesia on neural and hemodynamic activity. Finally, we established a causal relationship between cortical activation and hemodynamic responses by driving neurons not only with visual stimulation but also optogenetically. The results point to striking differences in neurovascular coupling between the awake and the anesthetized cortex, both in amplitude and in time course.

\section{Materials and Methods}

Experiments were conducted according to the UK Animals Scientific Procedures Act (1986). Mice were 8- to 20-week-old male C57BL/6J. For 


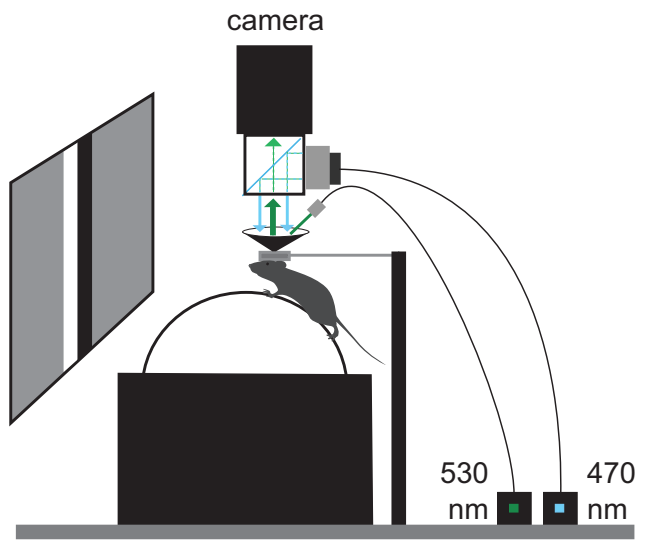

Figure 1. Experimental setup. The spherical treadmill with camera for intrinsic imaging, green LED (530 nm, for optical imaging) and blue LED (470 nm, for ChR2 stimulation); the monitor for visual stimulation and the head fixation system.

experiments involving optogenetics, we used transgenic mice that express Channelrhodopsin-2 (ChR2) in cortex [B6.CgTg(THy1-COP4/ EYFP), 9Gfng/j or $18 \mathrm{Gfng} / \mathrm{j}$, Arenkiel et al., 2007].

Initial surgery. For the implant surgery, we used isoflurane anesthesia (1-2\%), and injected an anti-inflammatory drug (carprofen [Rimadyl], 4 $\mathrm{mg} / \mathrm{kg}$, subcutaneously $[\mathrm{SC}])$. We maintained body temperature at $\sim 37^{\circ} \mathrm{C}$ using a heating pad and protected the eyes with artificial tears to prevent dryness (Viscotears; Novartis). We implanted a chronic head post and a stainless steel chamber, fixing them to the bone with dental cement (Sun Medical). To improve optical clarity, we used $N$-butyl cyanoacrylate (Vetbond; $3 \mathrm{M}$ ) to glue a 5 -mm-diameter glass coverslip inside the chamber. This preparation allowed high-quality imaging for up to 3 months. Imaging experiments started 3-4 d after recovery.

Treadmill. For experiments in awake mice, we placed the animal on a spherical treadmill (Harvey et al., 2009), a ball suspended on a stream of air (Fig. 1). Experiments typically lasted $\sim 1 \mathrm{~h}$. The mouse was free to run on the ball or stay stationary. We measured the movements of the treadmill with two optical mice. We classified each trial as running (as opposed to stationary) if the average running speed during the trial was $>1.6 \mathrm{~cm} / \mathrm{s}$, a value that separated two modes in the distribution of running speeds.

Anesthesia. To image during anesthesia, we replaced the treadmill with a heated pad. In most experiments, we anesthetized the mice with isoflurane $(1-2 \%)$. Experiments typically lasted $1-2 \mathrm{~h}$ and were followed by recovery. Three additional mice were anesthetized with urethane $(1 \mathrm{~g} / \mathrm{kg}$, intraperitoneally [IP]), preceded by an anti-inflammatory agent (Colvasone, $2 \mathrm{mg} / \mathrm{kg}$, intramuscularly), a sedative (Chlorprothixene, $10^{-5} \mathrm{mg} /$ $\mathrm{kg}$, IP), and an analgesic (Fentanyl, $0.05 \mathrm{mg} / \mathrm{kg}$, SC). These experiments were followed by euthanasia. Two mice were imaged both in wakefulness and under anesthesia.

Imaging. We illuminated the cortex with green light $(530 \pm 20 \mathrm{~nm})$ using a high-power LED (Thorlabs; Fig. 1). We acquired images at $10 \mathrm{~Hz}$ at $512 \times 512$ pixels $(2 \times 2$ binned $)$ using a CMOS camera (MV-D1024E160 ; Photonfocus) or a sCMOS camera (PCO.edge; PCO). In 10 experiments, we increased the temporal resolution to $25 \mathrm{~Hz}$ and doubled the spatial resolution, but neither changed the results. We placed a black cone between the camera and the chamber to shield the objective lens from the light of the monitors.

Visual stimuli. Stimuli were presented monocularly on three gammacorrected LCD monitors (NEC Multisync LCD 2190UXp or HannsG HW191, refresh rate $60 \mathrm{~Hz}$ ) arranged in a semicircle (radius $\sim 30 \mathrm{~cm}$ ) centered on the animal. Stimuli were periodic moving bars (Kalatsky and Stryker, 2003) or stationary flickering bars (Schuett et al., 2002). We used periodic moving bars in 23 experiments on 3 awake mice and 19 experiments on 3 mice anesthetized with isoflurane. Bars were $4^{\circ}$ wide and drifted slowly and periodically $(0.10-0.12 \mathrm{~Hz})$ across $60-90^{\circ}$ of contralateral visual field for 5-10 cycles. We used static flickering bars in 18 experiments on 3 awake mice and 11 experiments in 4 anesthetized mice
( 8 under isoflurane and 3 under urethane). Flickering bars were oriented vertically or horizontally and spanned $\sim 15^{\circ}$ while reversing in contrast at $2 \mathrm{~Hz}$. Waves were square with dominant spatial frequency of $0.2-0.4$ cycles $/{ }^{\circ}$ and $100 \%$ contrast presented in random positions in blocks presented 20-30 times.

Neural recordings. In separate experiments, we measured neural activity in V1 by replacing optical imaging with electrophysiological recordings. We measured responses to flickering bars under anesthesia (5 mice, 6 experiments, under urethane) and during wakefulness (6 mice, 12 experiments). We also measured responses to optogenetic stimulation in two homozygous $18 \mathrm{Gfng} / \mathrm{j}$ mice that were awake ( 2 experiments) and subsequently anesthetized with isoflurane (4 experiments).

The initial surgical preparation resembled that used for imaging experiments. We exposed the skull, implanted a head post, and performed a craniotomy under isoflurane (1-2\%). For recordings in anesthetized mice, we switched the anesthetic regime to urethane $(1 \mathrm{~g} / \mathrm{kg}, \mathrm{IP})$ and started neural recordings $\sim 30 \mathrm{~min}$ afterward. For experiments in awake mice, the implant surgery involved a chamber over visual cortex and recordings started at least 1 week after recovery. We protected the brain between recording days by filling the chamber with a removable siliconeelastomer plug (Kwik-Cast; World Precision Instruments). We acquired multiunit activity (MUA) at $30 \mathrm{kHz}$ using silicon electrodes (single shank, 16 contacts, $50 \mu \mathrm{m}$ spacing between contacts, $703 \mu \mathrm{m}^{2}$ area; NeuroNexus).

Optogenetics. To stimulate ChR2, we implanted five homozygous B6.CgTg (THy1-COP4/EYFP) mice. Three were $9 \mathrm{Gfng} / \mathrm{j}$, which express ChR2 in all cortical layers, and two were $18 \mathrm{Gfng} / \mathrm{j}$, which express ChR2 mostly in layer five. We performed seven experiments on five awake mice and three experiments on three mice anesthetized with isoflurane. We stimulated the cortex with $200 \mathrm{~ms}$ light pulses via a fiber-coupled highpower LED (Thorlabs) at $470 \mathrm{~nm}$. This wavelength matches the peak of the excitation spectrum of ChR2 (Zhang et al., 2006). We either used a collimator (CFC-2X-A; Thorlabs) or an epi-illumination system (Fig. 1) to produce an excitation spot with radius $\sim 2 \mathrm{~mm}$. We simultaneously imaged the cortex or recorded electrophysiologically, as described above.

To analyze responses to optogenetic stimulation, we subtracted the time average over $\sim 0.5 \mathrm{~s}$ of response before stimulation. Population averages for time course, amplitude, and delay were obtained as for responses to flickering bars (see below).

Retinotopic maps from periodic moving bars. To analyze the responses to periodic moving bars, we first removed global fluctuations, which are not stimulus driven. We concatenated the two spatial dimensions of each frame along a single vector, thus reducing the representation of the responses to a $2 \mathrm{D}$ matrix $D(x, t)$. We then performed singular value decomposition to obtain a spatial vector $f(x)$ and a temporal vector $g(t)$, the product of which accounted for $94.6 \pm 0.4 \%(n=42)$ of the variance and reflects the global fluctuations as follows:

$$
D(x, t)=f(x) g(t)+R(x, t)
$$

The desired signals are the residuals $R(x, t)$, which reflect the retinotopic, stimulus-evoked responses. These typically oscillated in time with the periodicity of the stimulus. We used the phase of this oscillation to calculate the delay of the stimulus-evoked response at each pixel. We then canceled the hemodynamic delay by subtracting the delays from stimuli moving in opposite directions, thus obtaining maps of retinotopy (Kalatsky and Stryker, 2003).

To measure the amplitude of the hemodynamic responses, we defined a square region of interest (ROI) including pixels with clear positional tuning (amplitude of the Fourier component at the stimulus frequency greater than the 20th percentile). Next, we averaged across pixels in the ROI and across stimulus cycles and, finally, we defined the amplitude as the absolute difference between the maximum and the minimum of this mean cycle response.

To measure power spectral densities, we computed, for each pixel, the phase of the Fourier component at the frequency of stimulation. We then used these phases to bin the pixels in $2^{\circ}$ intervals and averaged the time courses of pixels in each phase bin. We computed power spectral densities for each phase bin and averaged the results across bins. 

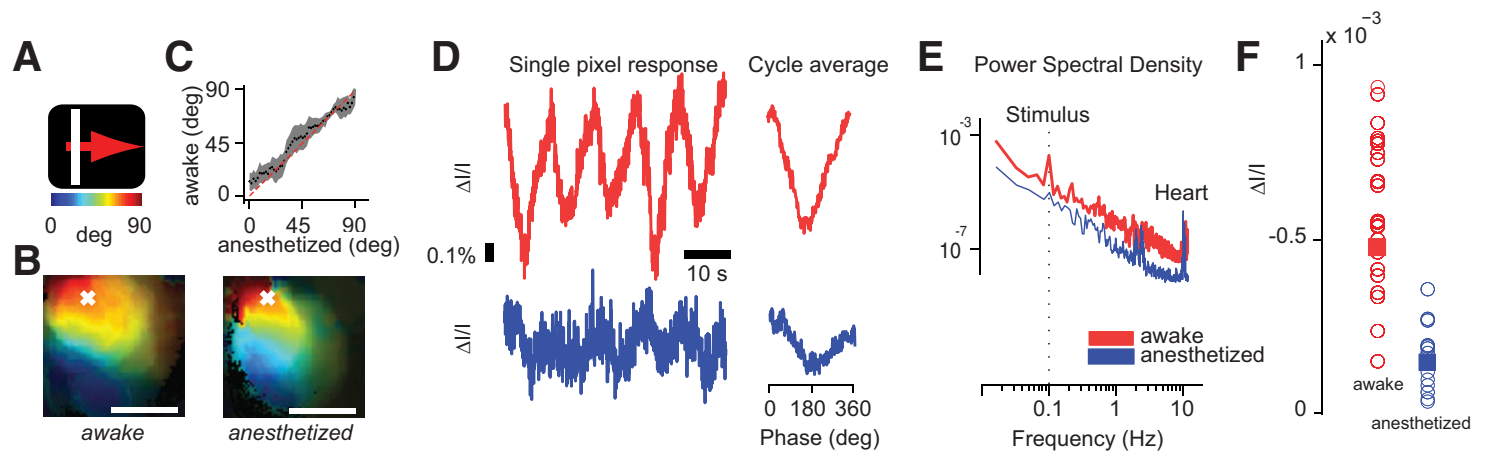

Figure 2. Hemodynamic responses to periodic moving bars in mouse V1 in wakefulness and anesthesia. A, Moving bar stimulus ( $4^{\circ}$ wide drifting at $0.1 \mathrm{~Hz}$ for 5 cycles) and color bar mapping degrees of visual field to the position of the bar on the screen. $\boldsymbol{B}$, Maps of retinotopy for a mouse in awake (left) and anesthetized (right) conditions. Colors map degrees of visual field on the azimuth. Brightness indicates signal amplitude. Scale bar, $1 \mathrm{~mm}$. For display purposes, in this and subsequent figures, we low-pass filtered the maps in space (cutoff 3 cycles/mm). C, Comparison of azimuth preference for the maps shown in $\boldsymbol{B}$. We considered pixels with amplitude $>15$ th percentile. Pixels were binned according to their preference in anesthetized condition (abscissa). For each bin, we then computed the average preferred position measured in the awake condition (ordinate). Gray regions, \pm 1 SD. $\boldsymbol{D}$, Time courses of activity for the pixel marked with a white cross in $\boldsymbol{B}$ for the whole stimulus (left) and averaged across cycles (right), awake (red trace), and anesthetized (blue trace). $\boldsymbol{E}$, Examples of power spectral density in awake and anesthetized conditions. A peak at frequencies of $\sim 10 \mathrm{~Hz}$ was present in both responses and reflected the heart rate. Dotted line indicates the frequency of the stimulus. $\boldsymbol{F}$, Summary of amplitudes for all experiments, 23 awake (red circles) and 19 anesthetized (blue circles). Squares indicate mean amplitudes for each condition.

Retinotopic maps from flickering bars. To analyze the responses to flickering bars, we averaged across stimulus repetitions to obtain a mean response to each stimulus $s, D_{s}(x, t)$. We then subtracted the mean response over time to a gray screen, $\left\langle D_{\text {blank }}(x, t)\right\rangle_{t}$, and divided the result by the mean response over space and time $\langle D(x, t)\rangle_{x, t}$ as follows:

$$
R_{s}(x, t)=\frac{D_{s}(x, t)-<D_{\text {blank }}(x, t)>_{t}}{<D_{s}(x, t)>_{x, t}}
$$

To obtain a single time course, $E(t)$, we averaged in space across of all pixels within a ROI and across all stimuli. We low-pass filtered this response (cutoff frequency at $4 \mathrm{~Hz}$ ) as follows:

$$
E(t)=F\left[<R_{s}(x, t)>_{x, s}\right]
$$

where $F$ is a low-pass-filtering operator. We computed the amplitude, $A$, as the maximum deflection from baseline of this time course and the delay, $D$, as the time to reach this maximum value.

To obtain maps of retinotopy from hemodynamic responses to flickering bars presented at different positions, for each pixel, we fitted a Gaussian function to its amplitude tuning for different stimulus positions. The values of the azimuth or elevation for which this Gaussian curve had its peak indicated the retinotopic preferences for that pixel. The SD, constrained to be the same for all pixels, established the spatial selectivity of the responses.

Analysis of neural responses. To analyze neural responses to flickering bars, we computed firing rates by averaging MUA in $16.7 \mathrm{~ms}$ time bins and averaging across stimulus repetitions. For each active contact site $s$ (second harmonic $>5$ spikes/s), we computed the firing rate, $R(t, s, p)$, at each stimulus position, $p$, and selected the best stimulus position, $p(s)$, for which the mean firing rate was highest. We then averaged across sites to obtain a mean time course for the experiment as follows:

$$
E(t)=\left\langle R_{s}(t, s, p(s))\right\rangle_{s}
$$

From these traces, we computed the amplitude as the absolute value of the maximum of the curves after subtracting the baseline response and the delay as the time to reach this maximum value. Population responses were obtained by averaging together all of the experiments.

Statistics. Except when noted otherwise, $p$-values reported are obtained from $t$ tests. In the figures, ${ }^{*} p<0.05,{ }^{* *} p<0.01$, and ${ }^{* *} p<$ 0.001 .

\section{Results}

We measured hemodynamic responses using optical imaging in mouse area V1 during visual stimulation (Fig. 1). We illuminated the cortex with a green light at $530 \mathrm{~nm}$. This wavelength is an isosbestic point in the absorbance spectra of oxy- and deoxyhemoglobin; that is, the point where the two spectra intersect. At this wavelength, absorbance changes reflect variations in blood volume, which has a close relationship to neural activity (Sirotin et al., 2009).

\section{Hemodynamic responses are larger in wakefulness than under anesthesia}

To study the effect of wakefulness and anesthesia on the amplitude of the hemodynamic response, we measured responses to periodic moving bars (Fig. $2 A-D$ ). The stimulus was a white bar drifting slowly across the contralateral visual field and cycling across the screen with a period of $10 \mathrm{~s}$ (Fig. $2 \mathrm{~A}$ ). As expected, the responses to this stimulus provided high-quality retinotopic maps of area V1 (Kalatsky and Stryker, 2003). The maps obtained during wakefulness were of comparable quality to those obtained under anesthesia (Fig. 2B). Reassuringly, similar maps were obtained when the same animal was imaged in the two conditions (Fig. 2C). As expected, the responses were periodic, oscillating at the stimulus frequency $0.1 \mathrm{~Hz}$, both in awake and in anesthetized mice (Fig. 2D).

The responses elicited by this stimulus were much larger in awake than in anesthetized mice (Fig. $2 D-F$ ). For example, the responses obtained from a representative pixel were 2.5 times larger in wakefulness than under anesthesia (Fig. 2D). A similar effect can be seen when plotting the power spectral density as a function of frequency (Fig. 2E). In wakefulness, there is more power at all frequencies and, in particular, there is an $\sim 1000$-fold increase at the peak at the stimulus frequency, 0.1 $\mathrm{Hz}$.

Similar effects were seen across animals and recordings: on average, responses measured during wakefulness were $\sim 4$ times larger than those measured under anesthesia (Fig. $2 F$ ). The amplitude of the hemodynamic response was $4.8 \pm 0.5\left(\Delta I / I^{\star} 10^{-4}\right)$ in wakefulness (SE, $N=24$ experiments in 3 mice) and a significantly lower $1.2 \pm 0.4$ under anesthesia $(\mathrm{SE}, N=19$ experiments in 3 mice, $p<0.001$ ). For two mice, we could compare directly the mean amplitudes in the two conditions and the differences were substantial. In the first mouse, the amplitude was $5.4 \pm 0.7$ $\left(\Delta I / I^{\star} 10^{-4}\right)$ in wakefulness ( $\mathrm{SE}, N=12$ experiments) versus 
$1.0 \pm 0.1$ under anesthesia $(\mathrm{SE}, N=10$, $p<0.001)$. In the second mouse, the amplitude was $5.0 \pm 0.9$ in wakefulness (SE, $N=8$ ) versus $0.6 \pm 0.1$ under anesthesia (SE, $N=7, p<0.001)$.

\section{Anesthesia does not influence the spatial extent of hemodynamic responses}

The periodic stimuli are an efficient method to obtain maps, but they confound the spatial aspect of the responses with the temporal aspect. To investigate whether anesthesia affected the spatial and temporal resolution of the hemodynamic response, we turned to stimuli that were episodic rather than periodic.

Specifically, we measured responses to counterphase flickering bars presented at different horizontal positions (Fig. 3). These stimuli were followed by a darkening of the cortex lasting for several seconds due to an increase in blood volume (Bonhoeffer and Grinvald, 1996). The spatial extent of the responses to flickering bars was similar in wakefulness and under anesthesia (Fig. 3B). For each pixel, we estimated the preferred position and the spatial spread of the response as the mean and SD of a Gaussian function fitted to the responses as a function of stimulus position (Fig. 3C). The average spatial spread across animals and recordings was not significantly different in the two conditions: $29 \pm 3^{\circ}$ in awake mice (SE, $N=18$ experiments in 3 mice) and $26 \pm 5^{\circ}$ in anesthetized mice (SE, $N=11$ experiments in 4 mice, $p>0.5$ ).

Therefore, although anesthesia had a profound effect on the amplitude of the hemodynamic response, it did not affect its spatial extent. Indeed, individual responses to flickering bars could be combined to yield high-quality retinotopic maps of area V1 (Schuett et al., 2002) whether a mouse was awake or anesthetized (Fig. $4 A, B$ ).

\section{Hemodynamic responses are faster in wakefulness than under anesthesia}

The flickering bars also allowed us to study the temporal properties of the responses, revealing profound differences between measurements performed in wakefulness and under anesthesia (Fig. 4C). When measured in wakefulness, the hemodynamic response was not only much larger, but also markedly faster than that measured under anesthesia (Fig. 4C).

These results were consistent across animals and experiments: hemodynamic responses measured during wakefulness were $\sim 1-3$ s faster than those measured under anesthesia (Fig. 4D,E). The responses in awake mice peaked earlier and returned to baseline faster than those in anesthetized mice (Fig. 4D). Delays were $2.2 \pm 0.4$ s during wakefulness ( $\mathrm{SE}, N=18$ ) and a significantly slower $4.3 \pm 0.6 \mathrm{~s}$ under isoflurane anesthesia (SE, $N=9, p<$ 0.001 ; Fig. $4 E)$.

The responses were also significantly larger for awake animals (Fig. $4 D, E$ ), confirming what was found earlier with responses to moving bars (Fig. 2). Response amplitudes (averaged over space) were $0.78 \pm 0.08 \%$ during wakefulness and a significantly lower $0.33 \pm 0.06 \%$ under isoflurane anesthesia $(p<0.001)$.

\section{Differences are not due to anesthetic type or behavioral state}

We have seen that there are dramatic differences in the amplitude and time course of hemodynamic responses in V1 of awake versus anesthetized mice. Next, we investigated whether we could further distinguish these effects based on additional factors: for anesthetized mice, the type of anesthesia, and for awake mice, the behavioral state. Neither factor proved to play a substantial role.

To assess the role of anesthesia, we measured the responses to flickering bars with an alternative anesthetic regime based on a single injection of urethane. Just as with isoflurane, this anesthetic led to hemodynamic responses with smaller amplitudes and slower dynamics than during wakefulness (Fig. 4E). The latency of the responses was $4.3 \pm 0.3 \mathrm{~s}(\mathrm{SE}, N=4)$, which was indistinguishable from that seen with isoflurane. At $0.48 \pm$ $0.11 \%$, however, response amplitude was slightly but significantly larger than under isoflurane $(p<0.01)$.

To assess the role of behavioral state, we investigated whether hemodynamic responses depended on locomotion (Fig. 5). Locomotion increases neural responses in V1 (Niell and Stryker, 2010; Ayaz et al., 2013) so we asked whether it could also increase hemodynamic responses. Awake animals spent a noticeable fraction of the time running, $26 \pm 8 \%(\mathrm{SE}, N=18)$, so we compared responses when awake mice were stationary versus when they were running (Fig. 5A,B). Hemodynamic responses were not significantly different in the two conditions $(0.91 \pm 0.06 \%$ vs $0.86 \pm 0.10 \%$, SE, $p>0.05$; Fig. $5 C$ ). Similarly, there was no significant difference in delay $(2.3 \pm 0.1$ vs $2.2 \pm 0.1 \mathrm{~s}, \mathrm{SE}, p>$ 0.05 ; Fig. $5 D$ ). In six mice, the imaging sessions contained at least $10 \%$ of trials in both the running and stationary conditions, allowing us to compare the hemodynamic responses within the same experiments. The resulting paired $t$ tests again indicated no statistical difference between running and stationary conditions $(p=0.5)$

The lack of effect of locomotion on hemodynamic responses is peculiar given that locomotion increases neural responses (Niell and Stryker, 2010; Ayaz et al., 2013). Perhaps this increase is offset by a decrease in the strength of neurovascular coupling, for example, due to changes in the dilation of blood vessels. We tried to test this explanation by measuring vessel diameter, but failed to 

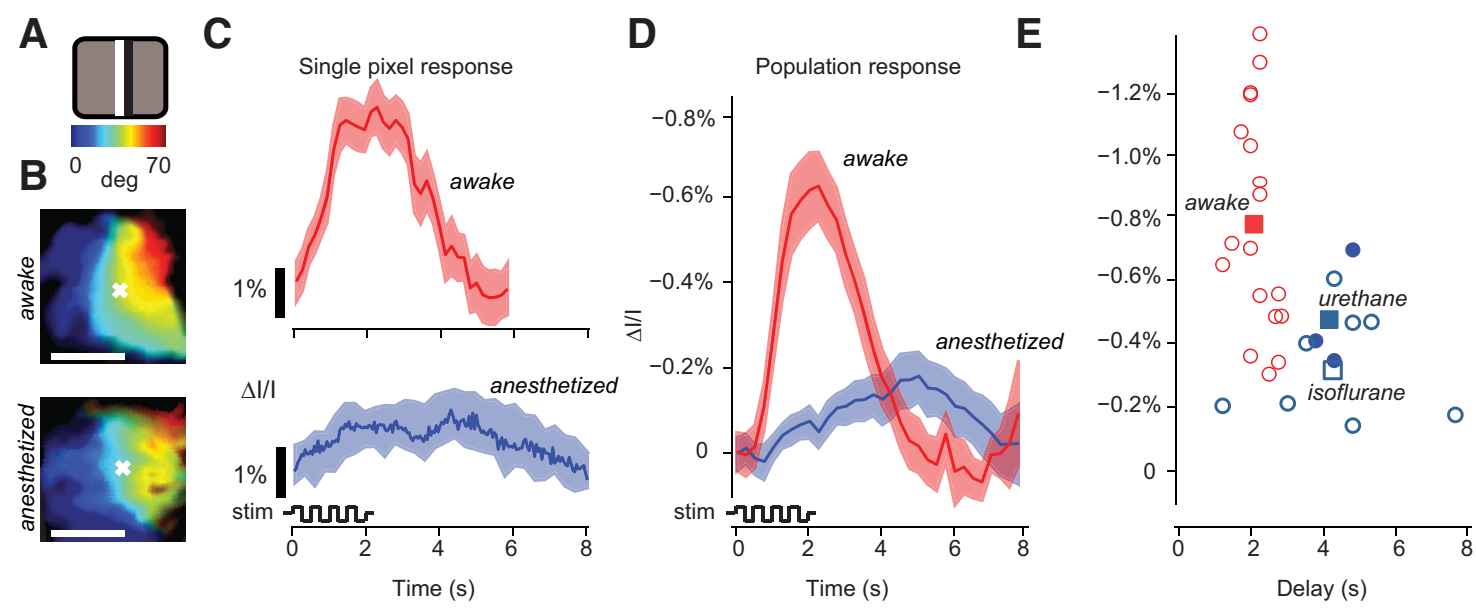

Figure 4. Temporal properties of hemodynamic responses to flashing bars in mouse $\mathrm{V} 1$ in wakefulness and anesthesia. $A$, Flickering bar stimulus $\left(15^{\circ}\right.$ wide, reversing in contrast at $2 \mathrm{~Hz}$ for $2 \mathrm{~s}$ ) Color bars map degrees of visual field to the position of the bar on the screen. $\boldsymbol{B}$, Maps of retinotopy for one example animal in awake (top) and anesthetized (bottom) conditions. Format is as in Figure $2 B$. $C$, Time courses of activity for the pixel marked with a white cross in $\boldsymbol{B}$, in wakefulness (top, red trace), and under anesthesia (bottom, blue trace). Shaded regions, \pm 1 SE. Bottom, Schematic of the luminance change of the stimulus flickering at $2 \mathrm{~Hz}$. D, Same as in C, averages across all pixels in the ROl (see Materials and Methods) in all experiments, 18 in wakefulness (red trace) and 11 under anesthesia (blue trace). $\boldsymbol{E}$, Amplitudes and delays for experiments in wakefulness (red circles) and under anesthesia (open blue circles, isoflurane; filled blue circles, urethane). Squares are means for each condition.

A

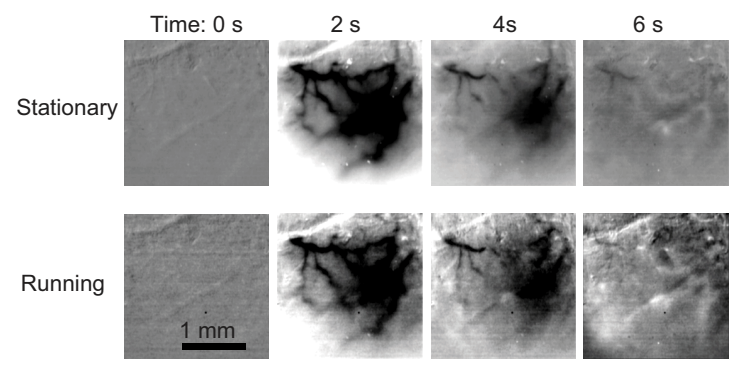

B

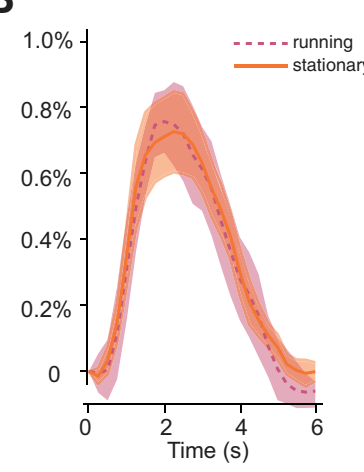

C

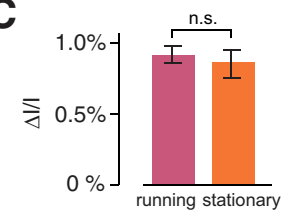

D

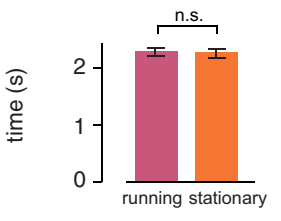

Figure 5. Hemodynamic responses to flashing bars in mouse $\mathrm{V} 1$ while the animal was running or stationary. $\boldsymbol{A}$, Responses to static flickering bars at four time points for one example animal while stationary (top) or running (bottom). B, Averages across all pixels in the Rol (see Materials and Methods) in 18 experiments ( $n=5$ mice) while the animal was stationary (ochre) and running (purple). C, Comparison of amplitudes in the two conditions. D, Same for delays computed as the time to reach the peak.

see any effect of locomotion (data not shown). However, the spatial resolution of our images may be insufficient for this analysis. Indeed, we could not even demonstrate variations in vessel diameter caused by visual stimulation. Measurements with twophoton microscopy in somatosensory cortex suggest that this variation is $\sim 10 \%$ (Sekiguchi et al., 2013). Most likely, the optical blur in our wide-field images obscures such small changes.

\section{Neural responses are similar in wakefulness and under anesthesia}

We next asked whether the difference between hemodynamic responses in awake and anesthetized conditions reflects a difference in the underlying neural responses (Fig. 6). We recorded spike activity via a multicontact silicon probe inserted in area $\mathrm{V} 1$, and we showed the same contrast-reversing stimuli used for optical imaging. As expected, the spike responses were periodic and oscillated at $4 \mathrm{~Hz}$, that is, at twice the stimulus frequency (Fig. 6A). Such responses could originate from complex cells and from pools of simple cells with different preferred spatial phases in their receptive fields (Movshon et al., 1978a, 1978b).

Anesthesia reduced neural responses only slightly, much less than it reduced hemodynamic responses. Response amplitude was $36 \pm 3$ spikes/s (SE, $N=12$ in 6 mice) in wakefulness compared with $31 \pm 6$ spikes/s under anesthesia (SE, $N=6$ in 5 mice). This difference was significant $(p<0.05)$ but small, almost one order of magnitude smaller than the large difference seen in hemodynamic responses (Fig. 6B). Indeed, wakefulness increased spike responses by only $16 \pm 24 \%$, whereas it increased the magnitude of hemodynamic responses by $111 \pm$ $38 \%(p<0.001$; Fig. $6 C)$.

Anesthesia also delayed neural responses but, once again, this effect was tiny compared with the effect seen in hemodynamic responses. Neural responses exhibited a significant difference in delay between the two conditions: $92 \pm 10 \mathrm{~ms}$ in wakefulness $(N=12)$ and $189 \pm 8 \mathrm{~ms}$ under anesthesia $(N=$ $6, p<0.001$ vs awake). However, this difference was almost 20 times smaller than that in hemodynamic responses (Fig. 6D). Indeed, anesthesia increased delay by only $97 \pm 8 \mathrm{~ms}$ in spike responses and by $2.1 \pm 0.7 \mathrm{~s}$ in hemodynamic responses $(p<$ 0.001; Fig. $6 E$ ).

These neural measurements, however, are likely to be dominated by pyramidal cells and should not be taken to apply to each individual type of neuron. For example, anesthesia silences inhibitory interneurons that express somatostatin (Adesnik et al., 
A

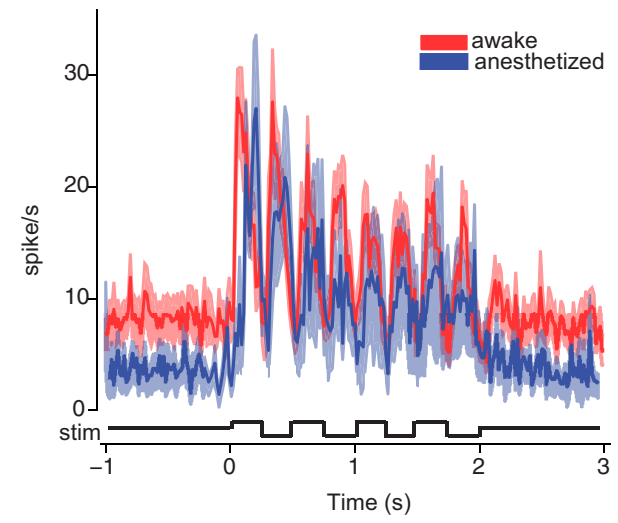

B
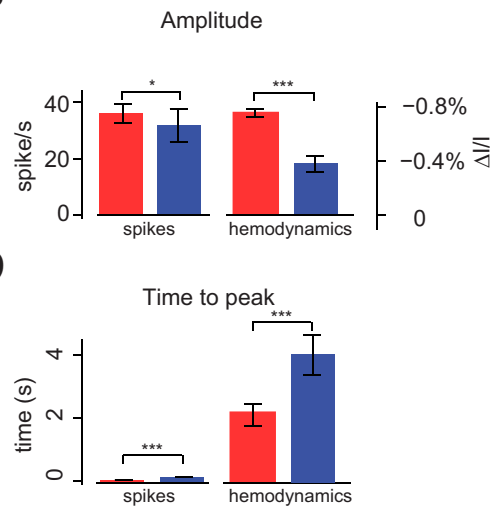

C

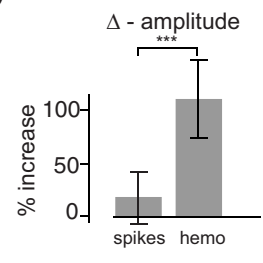

E

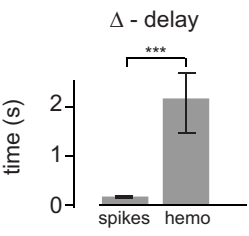

Figure 6. Neural responses to flashing bars in wakefulness and anesthesia. A, Average time courses of the responses for all animals and experiments, 12 in wakefulness (red trace), and six under anesthesia (blue trace). Shaded regions, \pm 1 SE. Bottom: Schematic of the luminance change of the stimulus, flickering at $2 \mathrm{~Hz}$. $B$, Mean peak amplitude of neural responses (left) and hemodynamic responses (right), colors as in $\boldsymbol{A}$. Error bars, \pm 1SE. C, Fractional amplitude change between awake and anesthetized conditions for spikes and hemodynamic responses. Error bars, \pm 1 SE. D, E, same as in $\boldsymbol{B}, \boldsymbol{C}$ for response delays computed as the time to reach the peak.

2012). To determine whether we could observe similar differential effects, we considered units with thin spikes (Barthó et al., 2004), which are putative interneurons expressing parvalbumin (DeFelipe et al., 2013). The distinction between thick spikes and thin spikes in our multiunit activity was not clear: in general, each site recorded both types of spikes. However, recordings at some sites were dominated by thin spikes (27/106 in wakefulness and 10/41 during anesthesia). Response amplitude did not differ significantly between these sites and the rest, either in wakefulness ( $39 \pm 11$ spikes/s vs $43 \pm 5$ spikes/s, $p>0.05)$ or under anesthesia (31 \pm 6 spikes/s vs $34 \pm 9$ spikes/s, $p>$ $0.05)$. Moreover, anesthesia reduced the amplitude of both groups similarly: by $5 \pm 7$ spikes/s in sites with thin spikes and by $12 \pm 9$ spikes/s in the remaining sites.

We conclude that the overall neural response does not show radical differences between the anesthetized and awake conditions. Both in terms of amplitude and of time course, the differences we measured are much smaller than those observed in hemodynamic responses (Fig. 4). The changes in the hemodynamic response with brain state must therefore arise either from subtle differences in the neural response, which are not apparent in the population rates, or, more likely, from a change in neurovascular coupling.

\section{Optogenetic cortical activation recapitulates the temporal effects}

To further test the hypothesis that wakefulness and anesthesia modify neurovascular coupling, we investigated whether the difference in the two conditions could be seen also in V1 responses evoked optogenetically, rather than through visual stimulation (Fig. 7). We measured hemodynamic responses to optogenetic stimulation in mice expressing $\mathrm{Chr}-2$ preferentially in pyramidal values for each condition.
B
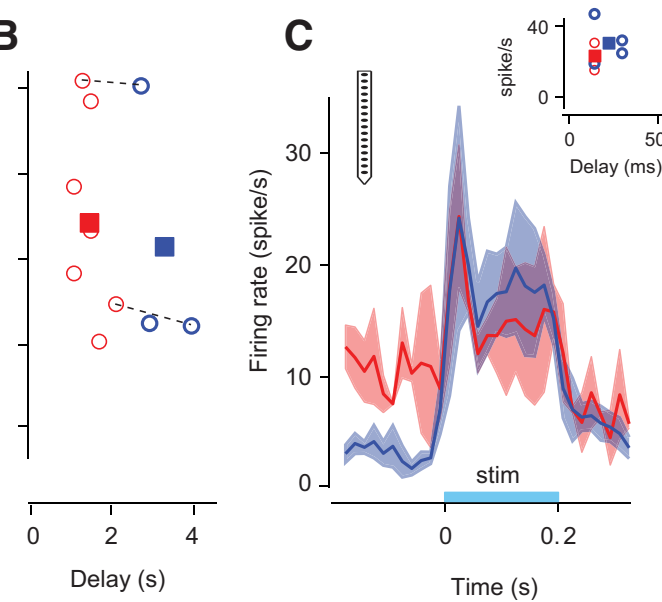

Figure 7. Hemodynamic and neural responses elicited by optogenetic stimulation in wakefulness and anesthesia. $\boldsymbol{A}$, Average time courses of the hemodynamic response across all pixels in the ROI (see Materials and Methods) in all experiments, seven in wakefulness (red trace) and three under anesthesia (blue trace). Shaded regions, $\pm 1 \mathrm{SE}$. Bottom, Time course of optical stimu, light-blue bar. A short pulse (200 ms) of blue light was flashed at the beginning of each trial. $\boldsymbol{B}$, Amplitudes and delays of emodynamic responses for wakefulness (red circles) and anesthesia (blue circles). Squares, Average values for each condition. Dashed lines are joining pairs of experiments performed in the same animal and in the same imaging session. $\boldsymbol{C}$, Average time xperiments in two mice under anesthesia (blue trace). Shaded regions, $\pm 1 \mathrm{SE}$. Bottom, Time course of optical stimulation, (ight-blue bar. A short pulse ( $200 \mathrm{~ms}$ ) of blue light was flashed at the beginning of each trial. Inset, Amplitudes (difference between peak and baseline) and delays of neural responses in wakefulness (red circles) and under anesthesia (blue circles). Squares, Average

excitatory neurons (Arenkiel et al., 2007). We flashed a brief pulse of blue light ( $470 \mathrm{~nm}, 200 \mathrm{~ms}, \sim 2 \mathrm{~mm}$ diameter) on the visual cortex and imaged the resulting hemodynamic response immediately after the flash offset. Consistent with previous studies (Desai et al., 2011; Kahn et al., 2011; Scott and Murphy, 2012), this optogenetic stimulation elicited strong hemodynamic responses (Fig. 7A).

The effects of anesthesia and wakefulness on the time courses recapitulated the effects seen with visual stimulation: responses peaked and returned to baseline faster in wakefulness than under anesthesia. On average, delays were $1.4 \pm 0.1 \mathrm{~s}$ in awake mice (SE, $N=7$ in 5 mice) and $3.1 \pm 0.4 \mathrm{~s}$ in anesthetized mice (SE, $N=3$ in 3 mice, $p<0.001$; Fig. 7B). These effects resemble those observed with visual stimulation (Fig. 4). 
A

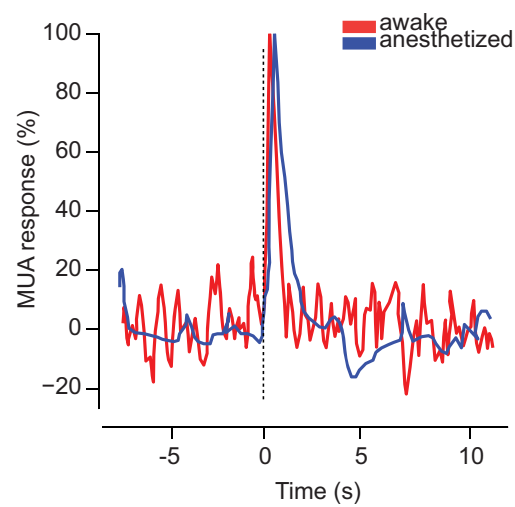

B

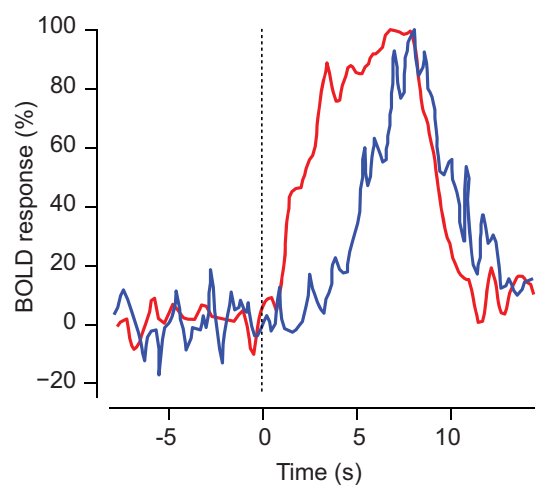

Figure 8. Time course of neural response and BOLD responses in primary visual cortex of awake and anesthetized monkeys. $\boldsymbol{A}$, Neural responses (MUA) to rotating checkerboard patterns during wakefulness (red trace) and under anesthesia (blue trace). $\boldsymbol{B}$, Same as in $\boldsymbol{A}$, but for BOLD responses. Data for anesthetized monkeys are from Figure 3 ( in Logothetis et al. (2001). Data for awake monkeys are from Figure $3 B$ in Goense and Logothetis (2008). Curves were replotted using an image processing algorithm for data extraction (MATLAB FileExchange, "grabit.m").

However, the amplitude of the hemodynamic response was approximately equal in the two conditions: $0.5 \pm 0.1 \%$ in wakefulness and $0.4 \pm 0.2 \%$ under anesthesia $(p>0.05)$. For two mice, we could compare the two conditions directly. For the first mouse, the amplitude was $0.81 \pm 0.17 \%$ in wakefulness and $0.80 \pm 0.24 \%$ under anesthesia (SD across repeats, $N=20$ ). In the second mouse, the amplitude was $0.29 \pm 0.11 \%$ in wakefulness and $0.24 \pm 0.13 \%$ under anesthesia (SD across repeats, $N=$ $20)$. In both cases, the difference was not significant $(p>0.05)$. There is therefore a difference between the effects of anesthesia on visual responses and on optogenetic responses: anesthesia reduces the amplitude of the former but not of the latter. This discrepancy may indicate that the amplitude and delay of the hemodynamic response are regulated by different mechanisms.

These results reflect the effects of anesthesia on neurovascular coupling, not its effects on neuronal activity. Indeed, control measurements established that firing rates evoked by optogenetic stimulation were similar between the two conditions (Fig. 7C). The differences in delay were $10-20 \mathrm{~ms}$ at most. The peak firing rate evoked by optical stimulation was similar in the two conditions and, because the baseline activity was higher in wakefulness, the response amplitude was actually larger under anesthesia $(31 \pm 6$ spikes/s) than in wakefulness $(24 \pm 5$ spikes/s, $p>0.05)$. These effects cannot account for those measured with hemodynamic responses, suggesting that the main effects of anesthesia on hemodynamic responses are due to changes in neurovascular coupling.

\section{Discussion}

We have shown that visual stimulation results in strong and rapid hemodynamic responses in primary visual cortex of awake mice and that both the amplitude and time course of neurovascular coupling depend critically on anesthesia and wakefulness. We ascribe these effects to neurovascular coupling because they were not accompanied by differences in spike responses (at least at the level of population rates) and they were replicated (at least in time course) by direct optogenetic stimulation of the cortex.

These results indicate that hemodynamic activity in mice is best measured during wakefulness. Indeed, in awake mice, we routinely obtained clear maps of retinotopy of quality comparable if not superior to those obtained under anesthesia. Hemodynamic responses were larger and faster than under anesthesia and were similar whether the mice were sitting or running. If one's experiment instead requires anesthesia, then it seems better to use urethane than isoflurane: under isoflurane, responses were more variable in time and across repeats and lower in amplitude than under urethane or during wakefulness.

The broad similarity between the effects of isoflurane and urethane suggests that changes in glutamate release are not the only reason for the effects reported here. Glutamate release is a key factor in neurovascular coupling and is suppressed by isoflurane (Haseneder et al., 2004; Wu et al., 2004). Conversely, urethane acts on several neurotransmitters (Hara and Harris, 2002) but spares glutamate release (Sceniak and Maciver, 2006).

In our experiments, locomotion did not have a significant effect on hemodynamic responses to visual stimulation. This result may appear peculiar, given that physical exercise is thought to increase cerebral blood flow (Querido and Sheel, 2007) and that locomotion increases neural responses (Niell and Stryker, 2010; Ayaz et al., 2013), including oscillations in the gamma range (30-80 Hz; Niell and Stryker, 2010), which are in turn associated with hemodynamic activity (Koch et al., 2009; Muthukumaraswamy et al., 2009). However, our analysis of locomotion effects focused exclusively on visually evoked responses in primary visual cortex. Moreover, we did not measure functional hyperemia directly, but rather an intrinsic signal only partially caused by vascular component. Locomotion may well affect other aspects of the signals or it may affect signals in different areas, which we did not investigate.

Our results about the effects of anesthesia extend to the mouse previous findings of numerous studies. Anesthesia has been shown to decrease the strength of neurovascular coupling, both in rats (Peeters et al., 2001; Martin et al., 2006) and in monkeys (Shtoyerman et al., 2000; Chen et al., 2005; Goense and Logothetis, 2008). Furthermore, studies in rats indicate that anesthesia lengthens the time course of neurovascular coupling and increases its overall latency (Martin et al., 2006; Masamoto et al., 2009). The agreement with rat data is particularly reassuring given that doubts are voiced regarding the similarity of neurovascular coupling in rats and mice (Prakash et al., 2007).

Our findings also agree, at least in part, with a study that performed $\mathrm{fMRI}$ measurements during optogenetic stimulation (Desai et al., 2011). In that study, anesthesia was shown to decrease the amplitude of the hemodynamic response and to have a variety of effects on its latency. In primary somatosensory cortex, the latency was essentially unaffected, whereas in downstream areas, it was significantly increased. Our results with optical imaging during optogenetic stimulation point to larger and more consistent effects of anesthesia on response latency.

Our results, however, appear to disagree with a study performed in primates, which stated that anesthesia does not affect the time course of neurovascular coupling (Shtoyerman et al., 2000). This difference in results may be ascribed to the difference in species or to other factors.

Nonetheless, our results do seem consistent with some measurements in primates, those obtained by Logothetis et al. (Fig. 8 ). We examined the BOLD responses and neural responses they 
measured under anesthesia (Logothetis et al., 2001) and in wakefulness (Goense and Logothetis, 2008). The two datasets involved similar stimulation protocols, which elicited neural responses with similar time courses (Fig. 8A). However, as we have observed in mouse, the hemodynamic response was profoundly affected by anesthesia, with a much shorter delay ( $1-2 \mathrm{~s}$ vs $\sim 5 \mathrm{~s}$ ) in wakefulness than under anesthesia (Fig. 8B). The different duration of the responses might reflect the different duration of the stimuli ( $4 \mathrm{~s}$ for anesthetized monkeys, $6 \mathrm{~s}$ for awake monkeys), although this difference did not seem to affect the duration of the spike responses (Fig. 8A).

It has long been known that an increase in neural activity is followed by a localized increase in blood supply (Roy and Sherrington, 1890), but the relationship between neural and blood signals is the subject of debate (Fox et al., 1988; Devor et al., 2011). A key factor in neurovascular coupling seems to be a feedforward mechanism initiated by excitatory synaptic activity, specifically by the release of glutamate from excitatory neurons (Attwell et al., 2010; Lecrux et al., 2011). Our results are consistent with this view, because optogenetic activation of pyramidal cells was sufficient to elicit a hemodynamic response and must have led to glutamate release.

Although neural activity is often thought to be the principal cause of the hemodynamic response, other factors play a role. One intriguing study (Sirotin and Das, 2009) showed that hemodynamic signals in visual cortex of alert monkeys may occur even without readily observable changes in local neural activity. This finding seems to suggest a preparatory mechanism bringing additional arterial blood to match the expected energy demand and supports the idea that multiple behavioral or physiological factors may influence hemodynamic activity.

Future work will be needed to reveal the mechanism through which anesthesia alters the physiology of cortical hemodynamics, producing weaker and slower responses. One possibility is that, during anesthesia, blood vessels are already quite dilated even before the presentation of a stimulus, so the effect of further dilation in increasing blood flow is attenuated. Indeed, isoflurane causes vasodilation in humans (Sessler et al., 1991) and urethane has similar properties in hamsters (Colantuoni et al., 1984). Measuring baseline vessel diameters in the same animal while awake or anesthetized could provide a key test of this hypothesis. As we have seen, such a measure will likely require two-photon imaging rather than the wide-field imaging technique that we used here. Another possibility for the effects of anesthesia on hemodynamic activity may lie in the balance of cortical excitation and inhibition. Indeed, visual stimulation evokes stronger cortical inhibition during wakefulness than under anesthesia (Haider et al., 2013) and GABAergic interneurons are known to modulate functional hyperemia (Lecrux et al., 2011). These all seem to be promising areas for further research.

\section{References}

Adesnik H, Bruns W, Taniguchi H, Huang ZJ, Scanziani M (2012) A neural circuit for spatial summation in visual cortex. Nature 490:226-231. CrossRef Medline

Arenkiel BR, Peca J, Davison IG, Feliciano C, Deisseroth K, Augustine GJ, Ehlers MD, Feng G (2007) In vivo light-induced activation of neural circuitry in transgenic mice expressing channelrhodopsin-2. Neuron 54: 205-218. CrossRef Medline

Attwell D, Iadecola C (2002) The neural basis of functional brain imaging signals. Trends Neurosci 25:621-625. CrossRef Medline

Attwell D, Buchan AM, Charpak S, Lauritzen M, Macvicar BA, Newman EA (2010) Glial and neuronal control of brain blood flow. Nature 468:232243. CrossRef Medline

Ayaz A, Saleem AB, Schölvinck ML, Carandini M (2013) Locomotion con- trols spatial integration in mouse visual cortex. Curr Biol 23:890-894. CrossRef Medline

Barthó P, Hirase H, Monconduit L, Zugaro M, Harris KD, Buzsaki G (2004) Characterization of neocortical principal cells and interneurons by network interactions and extracellular features. J Neurophysiol 92:600-608. CrossRef Medline

Bonhoeffer T, Grinvald A (1996) Optical imaging based on intrinsic signals. The methodology. In: Brain mapping: the methods (Toga AW, Mazziotta JC, eds), pp 55-97. London: Academic.

Boynton GM, Engel SA, Glover GH, Heeger DJ (1996) Linear systems analysis of functional magnetic resonance imaging in human V1. J Neurosci 16:4207-4221. Medline

Cang J, Kalatsky VA, Löwel S, Stryker MP (2005) Optical imaging of the intrinsic signal as a measure of cortical plasticity in the mouse. Vis Neurosci 22:685-691. Medline

Cardoso MM, Sirotin YB, Lima B, Glushenkova E, Das A (2012) The neuroimaging signal is a linear sum of neurally distinct stimulus- and taskrelated components. Nat Neurosci

Chen LM, Friedman RM, Roe AW (2005) Optical imaging of SI topography in anesthetized and awake squirrel monkeys. J Neurosci 25:7648-7659. CrossRef Medline

Colantuoni A, Bertuglia S, Intaglietta M (1984) Effects of anesthesia on the spontaneous activity of the microvasculature. Int J Microcirc Clin Exp 3:13-28. Medline

DeFelipe J, López-Cruz PL, Benavides-Piccione R, Bielza C, Larrañaga P, Anderson S, Burkhalter A, Cauli B, Fairén A, Feldmeyer D, Fishell G, Fitzpatrick D, Freund TF, González-Burgos G, Hestrin S, Hill S, Hof PR, Huang J, Jones EG, Kawaguchi Y, et al. (2013) New insights into the classification and nomenclature of cortical GABAergic interneurons. Nat Rev Neurosci 14:202-216. CrossRef Medline

Desai M, Kahn I, Knoblich U, Bernstein J, Atallah H, Yang A, Kopell N, Buckner RL, Graybiel AM, Moore CI, Boyden ES (2011) Mapping brain networks in awake mice using combined optical neural control and fMRI. J Neurophysiol 105:1393-1405. CrossRef Medline

Devor A, Sakadzic S, Saisan PA, Yaseen MA, Roussakis E, Srinivasan VI, Vinogradov SA, Rosen BR, Buxton RB, Dale AM, Boas DA (2011) "Overshoot" of $\mathrm{O}(2)$ is required to maintain baseline tissue oxygenation at locations distal to blood vessels. J Neurosci 31:13676-13681. CrossRef Medline

Fox PT, Raichle ME, Mintun MA, Dence C (1988) Nonoxidative glucose consumption during focal physiologic neural activity. Science 241:462464. CrossRef Medline

Goense JB, Logothetis NK (2008) Neurophysiology of the BOLD fMRI signal in awake monkeys. Curr Biol 18:631-640. CrossRef Medline

Haider B, Häusser M, Carandini M (2013) Inhibition dominates sensory responses in the awake cortex. Nature 493:97-100. Medline

Hara K, Harris RA (2002) The anesthetic mechanism of urethane: the effects on neurotransmitter-gated ion channels. Anesth Analg 94:313-318, table of contents. Medline

Harvey CD, Collman F, Dombeck DA, Tank DW (2009) Intracellular dynamics of hippocampal place cells during virtual navigation. Nature 461: 941-946. CrossRef Medline

Haseneder R, Kurz J, Dodt HU, Kochs E, Zieglgänsberger W, Scheller M, Rammes G, Hapfelmeier G (2004) Isoflurane reduces glutamatergic transmission in neurons in the spinal cord superficial dorsal horn: evidence for a presynaptic site of an analgesic action. Anesth Analg 98:1718 1723 , table of contents. Medline

Heeger DJ, Huk AC, Geisler WS, Albrecht DG (2000) Spikes versus BOLD: what does neuroimaging tell us about neuronal activity? Nat Neurosci 3:631-633. CrossRef Medline

Kahn I, Desai M, Knoblich U, Bernstein J, Henninger M, Graybiel AM, Boyden ES, Buckner RL, Moore CI (2011) Characterization of the functional MRI response temporal linearity via optical control of neocortical pyramidal neurons. J Neurosci 31:15086-15091. CrossRef Medline

Kalatsky VA, Stryker MP (2003) New paradigm for optical imaging: temporally encoded maps of intrinsic signal. Neuron 38:529-545. CrossRef Medline

Kaneko M, Stellwagen D, Malenka RC, Stryker MP (2008) Tumor necrosis factor-alpha mediates one component of competitive, experiencedependent plasticity in developing visual cortex. Neuron 58:673-680. CrossRef Medline

Koch SP, Werner P, Steinbrink J, Fries P, Obrig H (2009) Stimulus-induced and 
state-dependent sustained gamma activity is tightly coupled to the hemodynamic response in humans. J Neurosci 29:13962-13970. CrossRef Medline

Lecrux C, Toussay X, Kocharyan A, Fernandes P, Neupane S, Lévesque M, Plaisier F, Shmuel A, Cauli B, Hamel E (2011) Pyramidal neurons are "neurogenic hubs" in the neurovascular coupling response to whisker stimulation. J Neurosci 31:9836-9847. CrossRef Medline

Logothetis NK, Pauls J, Augath M, Trinath T, Oeltermann A (2001) Neurophysiological investigation of the basis of the fMRI signal. Nature 412: 150-157. CrossRef Medline

Marcar VL, Schwarz U, Martin E, Loenneker T (2006) How depth of anesthesia influences the blood oxygenation level-dependent signal from the visual cortex of children. Am J Neuroradiol 27:799-805. Medline

Martin C, Martindale J, Berwick J, Mayhew J (2006) Investigating neuralhemodynamic coupling and the hemodynamic response function in the awake rat. Neuroimage 32:33-48. CrossRef Medline

Masamoto K, Fukuda M, Vazquez A, Kim SG (2009) Dose-dependent effect of isoflurane on neurovascular coupling in rat cerebral cortex. Eur J Neurosci 30:242-250. CrossRef Medline

Merlin S, Horng S, Marotte LR, Sur M, Sawatari A, Leamey CA (2013) Deletion of Ten-m3 induces the formation of eye dominance domains in mouse visual cortex. Cereb Cortex 23:763-774. CrossRef Medline

Movshon JA, Thompson ID, Tolhurst DJ (1978a) Receptive field organization of complex cells in the cat's striate cortex. J Physiol 283:79-99. Medline

Movshon JA, Thompson ID, Tolhurst DJ (1978b) Spatial summation in the receptive fields of simple cells in the cat's striate cortex. J Physiol 283:5377. Medline

Muthukumaraswamy SD, Edden RA, Jones DK, Swettenham JB, Singh KD (2009) Resting GABA concentration predicts peak gamma frequency and fMRI amplitude in response to visual stimulation in humans. Proc Natl Acad Sci U S A 106:8356-8361. CrossRef Medline

Niell CM, Stryker MP (2010) Modulation of visual responses by behavioral state in mouse visual cortex. Neuron 65:472-479. CrossRef Medline

Pearson RA, Barber AC, Rizzi M, Hippert C, Xue T, West EL, Duran Y, Smith AJ, Chuang JZ, Azam SA, Luhmann UF, Benucci A, Sung CH, Bainbridge JW, Carandini M, Yau KW, Sowden JC, Ali RR (2012) Restoration of vision after transplantation of photoreceptors. Nature 485:99-103. CrossRef Medline

Peeters RR, Tindemans I, De Schutter E, Van der Linden A (2001) Comparing BOLD fMRI signal changes in the awake and anesthetized rat during electrical forepaw stimulation. Magn Reson Imaging 19:821-826. CrossRef Medline

Prakash N, Biag JD, Sheth SA, Mitsuyama S, Theriot J, Ramachandra C, Toga AW (2007) Temporal profiles and 2-dimensional oxy-, deoxy-, and total-hemoglobin somatosensory maps in rat versus mouse cortex. Neuroimage 37:S27-S36. CrossRef Medline

Qiu M, Ramani R, Swetye M, Rajeevan N, Constable RT (2008) Anesthetic effects on regional CBF, BOLD, and the coupling between task-induced changes in CBF and BOLD: an fMRI study in normal human subjects. Magn Reson Med 60:987-996. CrossRef Medline

Querido JS, Sheel AW (2007) Regulation of cerebral blood flow during exercise. Sports Med 37:765-782. CrossRef Medline

Roy CS, Sherrington CS (1890) On the regulation of the blood-supply of the brain. J Physiol 11:85-117.

Sato M, Stryker MP (2008) Distinctive features of adult ocular dominance plasticity. J Neurosci 28:10278-10286. CrossRef Medline

Sceniak MP, Maciver MB (2006) Cellular actions of urethane on rat visual cortical neurons in vitro. J Neurophysiol 95:3865-3874. CrossRef Medline

Schuett S, Bonhoeffer T, Hübener M (2002) Mapping retinotopic structure in mouse visual cortex with optical imaging. J Neurosci 22:6549-6559. Medline

Scott NA, Murphy TH (2012) Hemodynamic responses evoked by neuronal stimulation via channelrhodopsin-2 can be independent of intracortical glutamatergic synaptic transmission. PLoS One 7:e29859. CrossRef Medline

Sekiguchi Y, Masamoto K, Takuwa H, Kawaguchi H, Kanno I, Ito H, Tomita Y, Itoh Y, Suzuki N, Sudo R, Tanishita K (2013) Measuring the vascular diameter of brain surface and parenchymal arteries in awake mouse. Adv Exp Med Biol 789:419-425. CrossRef Medline

Sessler DI, McGuire J, Moayeri A, Hynson J (1991) Isoflurane-induced vasodilation minimally increases cutaneous heat loss. Anesthesiology 74: 226-232. CrossRef Medline

Shtoyerman E, Arieli A, Slovin H, Vanzetta I, Grinvald A (2000) Long-term optical imaging and spectroscopy reveal mechanisms underlying the intrinsic signal and stability of cortical maps in $\mathrm{V} 1$ of behaving monkeys. J Neurosci 20:8111-8121. Medline

Sirotin YB, Das A (2009) Anticipatory haemodynamic signals in sensory cortex not predicted by local neuronal activity. Nature 457:475-479. CrossRef Medline

Sirotin YB, Hillman EM, Bordier C, Das A (2009) Spatiotemporal precision and hemodynamic mechanism of optical point spreads in alert primates. Proc Natl Acad Sci U S A 106:18390-18395. CrossRef Medline

Smith SL, Trachtenberg JT (2007) Experience-dependent binocular competition in the visual cortex begins at eye opening. Nat Neurosci 10:370375. CrossRef Medline

Southwell DG, Froemke RC, Alvarez-Buylla A, Stryker MP, Gandhi SP (2010) Cortical plasticity induced by inhibitory neuron transplantation. Science 327:1145-1148. CrossRef Medline

Wu XS, Sun JY, Evers AS, Crowder M, Wu LG (2004) Isoflurane inhibits transmitter release and the presynaptic action potential. Anesthesiology 100:663-670. CrossRef Medline

Zhang F, Wang LP, Boyden ES, Deisseroth K (2006) Channelrhodopsin-2 and optical control of excitable cells. Nat Methods 3:785-792. CrossRef Medline 